\title{
A Novel 5G LTE Antenna Design for Portable Devices
}

\author{
Wei-Chiang Jhang $\mathbb{D}$ and Jwo-Shiun Sun \\ Department of Electronic Engineering, National Taipei University of Technology, Taipei, Taiwan \\ Correspondence should be addressed to Wei-Chiang Jhang; t106369006@ntut.edu.tw
}

Received 26 May 2020; Revised 28 August 2020; Accepted 10 September 2020; Published 21 September 2020

Academic Editor: Atsushi Mase

Copyright (c) 2020 Wei-Chiang Jhang and Jwo-Shiun Sun. This is an open access article distributed under the Creative Commons Attribution License, which permits unrestricted use, distribution, and reproduction in any medium, provided the original work is properly cited.

\begin{abstract}
This paper presents the low profile, planar, and small-size antenna design for WWAN, LTE, and 5G (5th generation wireless systems) for use in portable communication equipment. The antenna occupies only $65 \times 13 \times 0.4 \mathrm{~mm}^{3}$, and the antenna is combined with a $200 \times 260 \mathrm{~mm}^{2}$ copper plate to simulated system ground plane. In the low band, a direct-fed right-side arm and a coupled-fed arm implemented can excite a $1 / 4 \lambda$ fundamental resonant mode at 0.85 and $0.76 \mathrm{GHz}$ to cover $0.698-0.96 \mathrm{GHz}$ and upper $3 / 4 \lambda$ and $5 / 4 \lambda$ resonant modes are controlled by L-shaped element at 2.34, 2.69, 3.4, and $4.0 \mathrm{GHz}$ to cover $1.71-2.69 \mathrm{GHz}$ and $3.2-4.2 \mathrm{GHz}$. The direct-fed left-side arm produced $1 / 4 \lambda$ to cover $5.15-5.85 \mathrm{GHz}$. In far-field measured, peak gain and efficiency in low, middle, and high bands are $0.43-5.67 \mathrm{dBi}$ and $55-86 \%$. Finally, experiments demonstrate that the present antenna exhibits a good performance for portable devices.
\end{abstract}

\section{Introduction}

The evolution of wireless system technology has enabled not only the miniaturization but also the multiband applicability of antenna systems of portable communication devices such as smartphones and laptops (notebooks (NBs)) [1-5]. In particular, not only laptops support wireless LAN (WLAN) but also developments have occurred with respect to $4 \mathrm{G} / 5 \mathrm{G}$ wireless systems [6-9]. A system with long-term evolution (LTE) and sub-6G (FR1) applications is thus required. The antennas inside portable devices must cover BW\% (bandwidth percentage) $=31.3 \%$ for low band; this antenna covered LTE $700(0.698-0.787 \mathrm{GHz})$, GSM $850(0.824-0.894 \mathrm{GHz})$, and GSM $900(0.88-0.96 \mathrm{GHz})$. At the middle band, the bandwidth percentage was $44.5 \%$, and it equalled GSM 1800 $(1.71-1.88 \mathrm{GHz})), \quad$ GSM $1900 \quad(1.85-1.99 \mathrm{GHz}), \quad$ UMTS $(1.92-2.17 \mathrm{GHz})$, and LTE $2500(2500-2690 \mathrm{MHz})$. At the high band, BW\% was $21 \%$ for $\mathrm{C}$ band $(3.4-4.2 \mathrm{GHz})$ and $\mathrm{BW} \%=12.7 \%$ for license-assisted access (LAA) $(5.15-5.85 \mathrm{GHz})[2-4,10]$. In current commercial communication equipment of STBR (screen-to-body ratio) is significant for user impression; thus, limited space is reserved for antennas. In particular, NBs and tablets have multiple smalldimension antennas above the screen such as two WIFI and two LTE antennas $[6,11]$; it is challenged for small-size antenna design. Thus, the antennas used in wireless equipment are required to be small as well as to exhibit a low profile. Previously executed research $[9,12]$ has proposed an approach for designing small antennas with a meander architecture. In other research studies $[3,8,10,13]$, meander structures with loop-type antennas were used to achieve a small equipment size. In addition, a bent arm was used by other researchers to design an antenna for multiband applications $[12,14]$. The present study was executed to design an antenna exhibiting low as well as high operating bands achieved by applying direct-fed and coupled-fed mechanisms; the derived bands can encompass the LTE, WWAN, C band (n77 and n78), and LAA application bands. In the proposed antenna, the arms have a small size and planar structure.

\section{Antenna Design}

An FR4 substrate constituted the basis for constructing the proposed antenna in Figures 1(a) and 1(b) and optimized dimensions in Table 1. Fabricated prototype antenna is shown in Figure 2 for measurement; the substrate's dielectric constant, thickness, and loss tangent were determined to be $4.4,0.4 \mathrm{~mm}$, and 0.02 , respectively. An NB and tablet's 


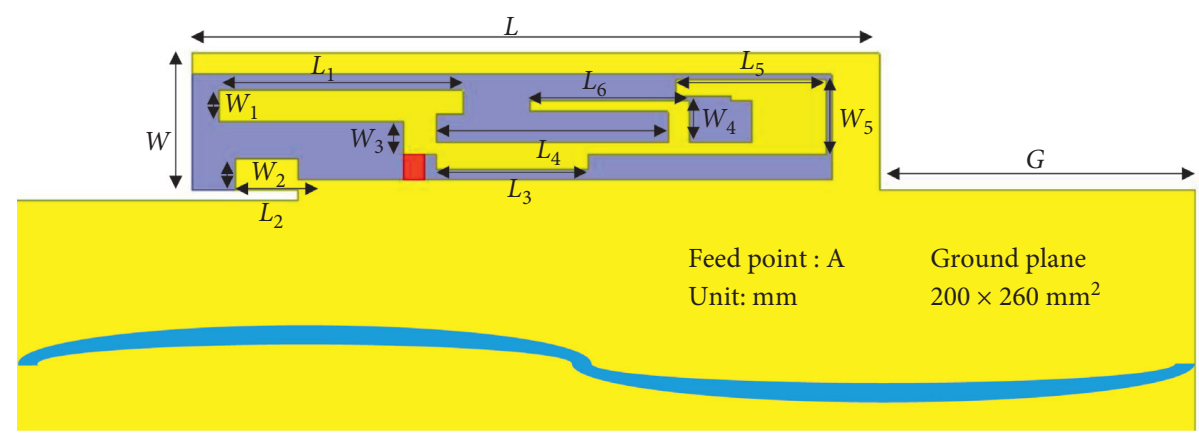

(a)

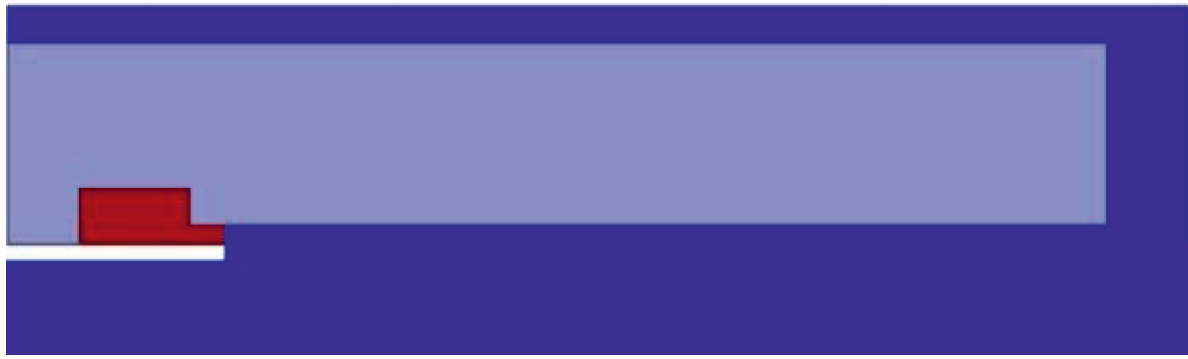

Couple-fed arm

Matching element of ground

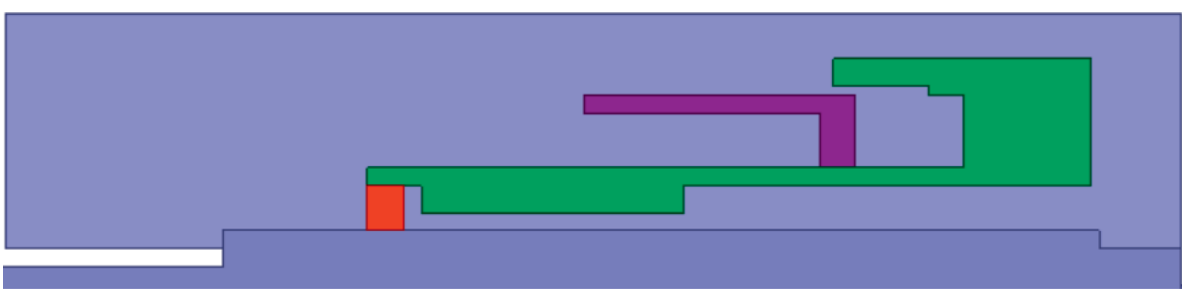

Right-side direct-fed arm

L-shaped matching element

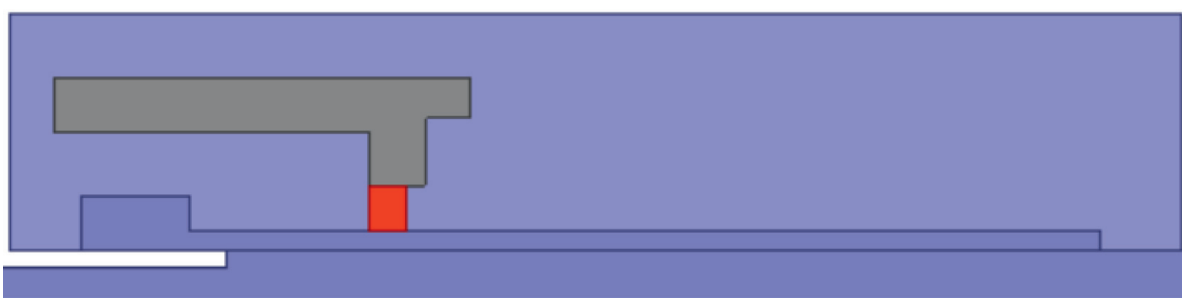

Left-side direct-fed arm

(b)

FIGURE 1: (a) Schematic of developed antenna's geometry; (b) definition of component.

TABle 1: Developed antenna's dimensions.

\begin{tabular}{|c|c|c|c|c|c|c|c|c|c|c|c|c|c|c|}
\hline Parameter & $L$ & $L_{1}$ & $L_{2}$ & $L_{3}$ & $L_{4}$ & $L_{5}$ & $L_{6}$ & $W$ & $W_{1}$ & $W_{2}$ & $W_{3}$ & $W_{4}$ & $W_{5}$ & $G$ \\
\hline Value $(\mathrm{mm})$ & 65 & 23 & 8 & 14.5 & 21.75 & 14.25 & 15 & 13 & 3 & 3 & 3 & 4 & 7 & 30 \\
\hline
\end{tabular}

ground plane were simulated by a 13 in screen measuring $200 \times 260 \mathrm{~mm}^{2}$. For the developed antenna, the space it would occupy was determined to measure $65 \times 13 \mathrm{~mm}^{2}$. Accordingly, the antenna can suitably be placed on the top side of the compartment of an NB or tablet. The aforementioned direct-fed arm implemented can excite a $1 / 4 \lambda$ fundamental resonant mode at $0.85 \mathrm{GHz}$ as well as upper $3 / 4$ $\lambda$ and $5.4 \lambda$ resonant modes at 2.69 and $4.0 \mathrm{GHz}$, respectively, 


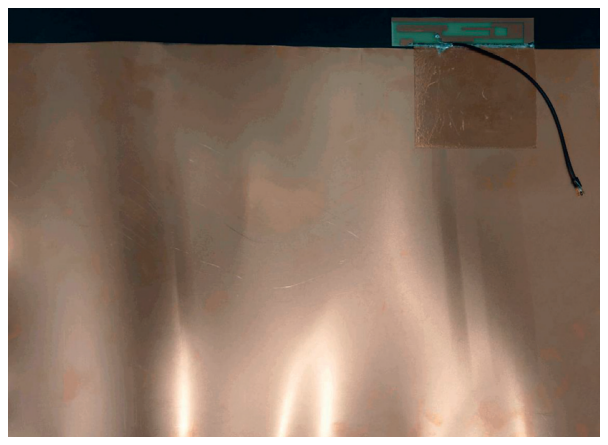

(a)

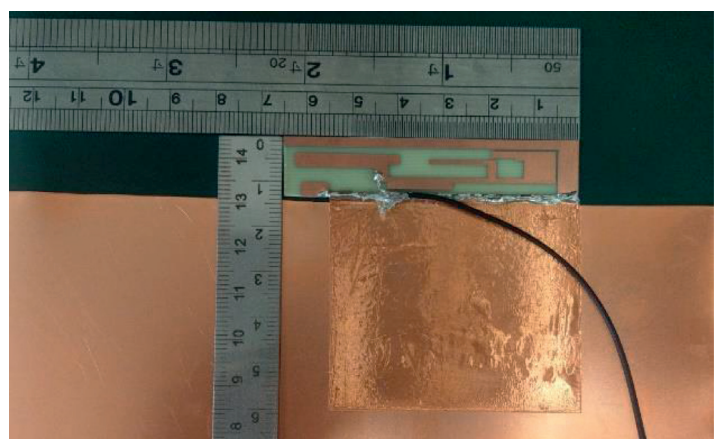

(b)

Figure 2: Prototype antenna.

on the right side. In addition, it can excite a $1 / 4 \lambda$ resonant mode at $5.5 \mathrm{GHz}$ on the left side. Moreover, the coupled-fed arm could excite a fundamental resonant mode at $0.76 \mathrm{GHz}$ and upper resonant modes of $3 / 4$ and $5.4 \lambda$ at 2.34 and $3.4 \mathrm{GHz}$, respectively. Through the integration of the two wide modes at 0.76 and $0.85 \mathrm{GHz}$, an operating range of $0.698-0.96 \mathrm{GHz}$ (bandwidth of $0.262 \mathrm{GHz}$ or $31.7 \%$ ) can be obtained. This range covers the GSM 850 and 900 as well as the LTE 700 application bands. The higher modes at 0.76 and $0.85 \mathrm{GHz}$ achieve an operating range of $1.7-2.7 \mathrm{GHz}$ (bandwidth of $0.99 \mathrm{GHz}$ or $45.1 \%$ ) for the DCS 1800 , PCS 1900, UMTS 2100, and LTE 2500 bands as well as the C band range of 3.3-4.2 GHz. The direct-fed arm on the left side has a fundamental resonant mode of $1 / 4 \lambda$ at $5.5 \mathrm{GHz}$ for the LAA $(5.15-5.85 \mathrm{GHz})$. For antenna testing in this study, one side of a coaxial cable was connected to the direct-fed arm and the other side was connected to the contact system ground plane, which was used to provide the RF signal input.

\section{Experimental Results and Parametric Study}

The derived $S_{11}$ values from the simulation executed through ANSYS HFSS software, and measurement in this study is displayed in Figure 3, indicating good agreement. The testing frequencies obtained for an $S_{11}$ value of $-6 \mathrm{~dB}$ covered the $2 \mathrm{G}$, $3 \mathrm{G}, 4 \mathrm{G}$, and $5 \mathrm{G}$ systems. Figure 4 (a) displays the simulated $S_{11}$ values for different coupled-fed arm lengths. Shortening $10 \mathrm{~mm}$ and $15 \mathrm{~mm}$ of the couple-fed arm induced the fundamental mode at $0.76 \mathrm{GHz}$ move to high levels of frequency as well as $0.76 \mathrm{GHz}$ higher modes of 2.34 and $3.4 \mathrm{GHz}$ move to a higher frequency. Figures 4(b)-4(d) display the coupled-fed arm current distribution at $0.76,2.34$, and $3.4 \mathrm{GHz}$, respectively. For the mode at $0.76 \mathrm{GHz}$, one null was observed for the couple-fed arm, as shown in Figure 3(b). Thus, the $0.76 \mathrm{GHz}$ fundamental mode was $1 / 4 \lambda$. For the mode at $2.34 \mathrm{GHz}$, two null values were observed for the couple-fed arm, as shown in Figure 4(c). Thus, $2.34 \mathrm{GHz}$ is a higher mode of $3 / 4 \lambda$. For the mode at $3.4 \mathrm{GHz}$, three null values were observed for the couple-fed arm, as shown in Figure $4(\mathrm{~d})$. Thus, $3.4 \mathrm{GHz}$ is a higher mode of $5 / 4 \lambda$.

Figure 5(a) displays the simulated $S_{11}$ values derived when different lengths were considered for the right-side direct-fed arm implemented on the right side. This direct-fed arm had a resonant fundamental mode at $0.85 \mathrm{GHz}$. When this arm was shortened $5 \mathrm{~mm}$ and $8 \mathrm{~mm}$, a $0.85 \mathrm{GHz}$ shift and mismatch were caused, and $0.85 \mathrm{GHz}$ higher mode of 2.69 and $4.0 \mathrm{GHz}$ moved to higher frequencies. Figures 5(b)5(d) illustrate the simulated current distribution of the rightside direct-fed arm at $0.85,2.69$, and $4.0 \mathrm{GHz}$, respectively. For the mode at $0.85 \mathrm{GHz}$, one null was observed for the direct-fed arm, as shown in Figure 5(b). Thus, $0.76 \mathrm{GHz}$ fundamental mode was $1 / 4 \lambda$. For the mode at $2.69 \mathrm{GHz}$, two null values were observed for the direct-fed arm, as shown in Figure 5(c). Thus, $2.69 \mathrm{GHz}$ is a higher mode of $3 / 4 \lambda$. For the mode at $4.0 \mathrm{GHz}$, three null values were observed for the direct-fed arm, as shown in Figure 5(d). Thus, $4.0 \mathrm{GHz}$ is a higher mode of $5 / 4 \lambda$.

Figure 6(a) displays the simulated $S_{11}$ values when the left-side direct-fed arm was adjusted in terms of length. The fundamental mode of this arm was $5.5 \mathrm{GHz}$. $5.5 \mathrm{GHz}$ fundamental mode moved toward higher frequencies as the arm was shortened. Figure 6(b) displays the simulated current 


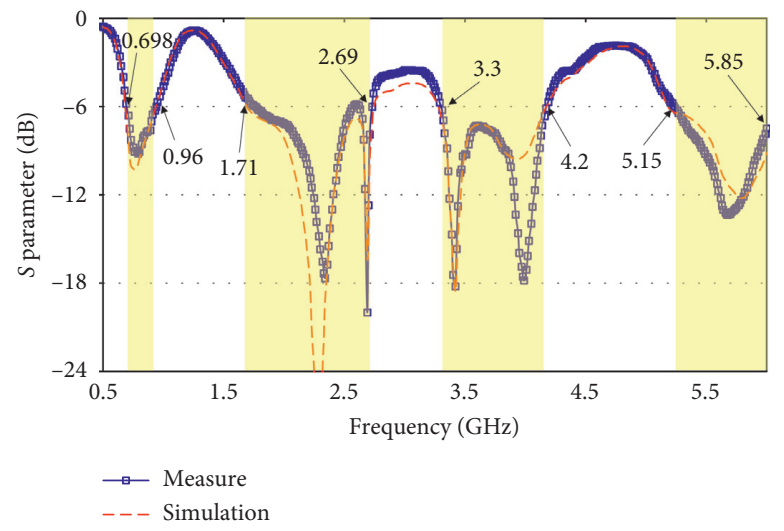

Figure 3: $S_{11}$ values derived from simulation and measurement.

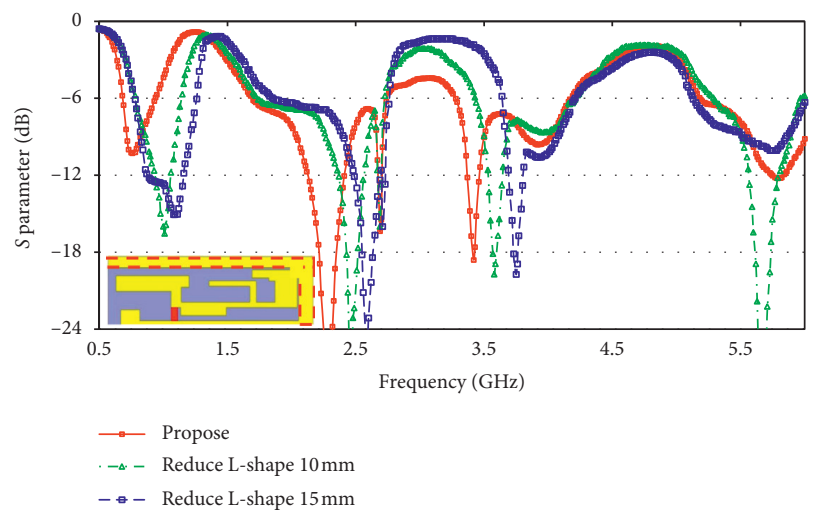

(a)

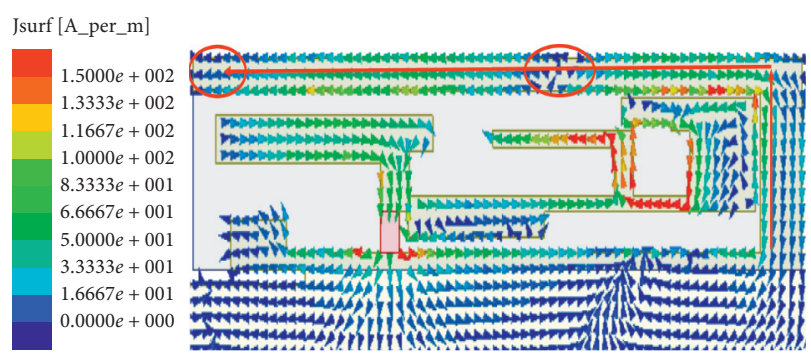

(c)

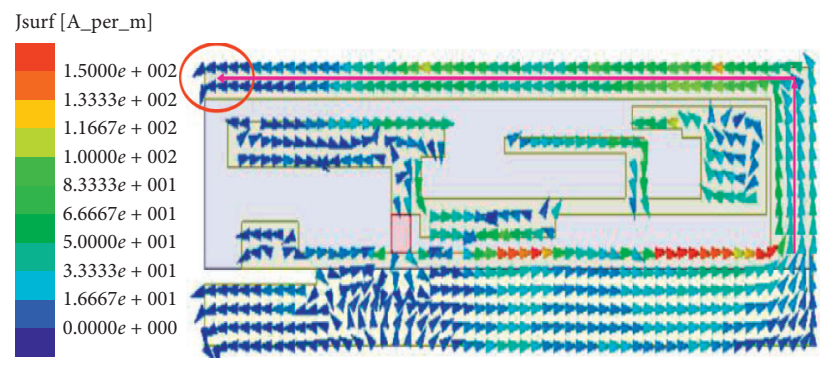

(b)
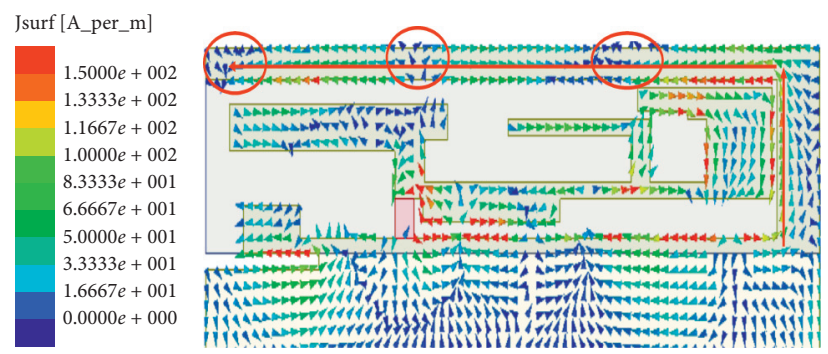

(d)

FIgURE 4: (a) $S_{11}$ values derived from simulation for various lengths of the coupled-fed arm of the developed antenna; couple-fed arm's current distribution at (b) 0.76 , (c) 2.34 , and (d) $3.4 \mathrm{GHz}$.

distribution of the left-side direct-fed arm at $5.5 \mathrm{GHz}$. $5.5 \mathrm{GHz}$ fundamental mode was $1 / 4 \lambda$.

Figure $7\left(\right.$ a) displays the simulated $S_{11}$ values obtained with and without a ground strip (matching element). The ground strip influenced antenna matching. Without a ground strip, the low and high modes changed with impedance. With a ground strip, the low operating band ended at $0.96 \mathrm{GHz}$ and the high operating band ended at $5.85 \mathrm{GHz}$. Figure 7 (b) presents the simulated $S_{11}$ values obtained when an inverted L-shaped matching element was and was not used. This element influenced the direct-fed arm at $4 \mathrm{GHz}$. Without the aforementioned matching element, a significant shift to high frequency occurred. With the matching, the operating band covered the frequency range from 3.3 to 4.2 $\mathrm{GHz}$.

Figure 8 displays the $2 \mathrm{D}$ antenna radiation patterns in the $x-z, x-y$, and $y-z$ planes at $760 \mathrm{MHz}, 850 \mathrm{MHz}$, $2340 \mathrm{MHz}, \quad 2690 \mathrm{MHz}, \quad 3400 \mathrm{MHz}, \quad 4000 \mathrm{MHz}$, and $5500 \mathrm{MHz}$. The $x-y$ plane pattern is shown to be omnidirectional because 760,850 , and $5500 \mathrm{MHz}$ represent the base modes. Figures 9-11 display the measured efficiency and gain in the lower band as well as in the upper band. The antenna gain was determined to be $0.43-1.94 \mathrm{dBi}(1.51 \mathrm{dBi}$ variation) in the lower band (Figure 9), with the 

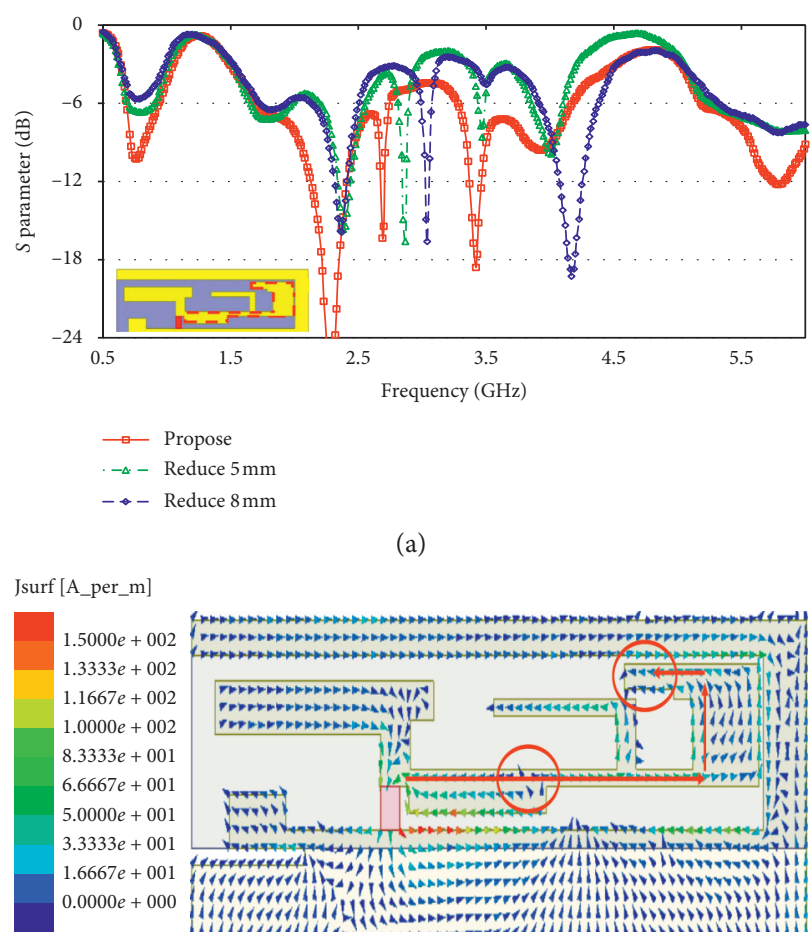

(a)

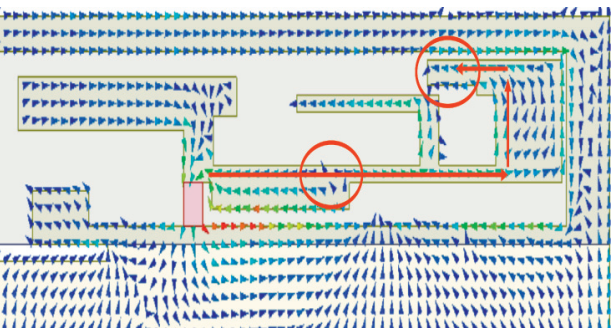

(c)
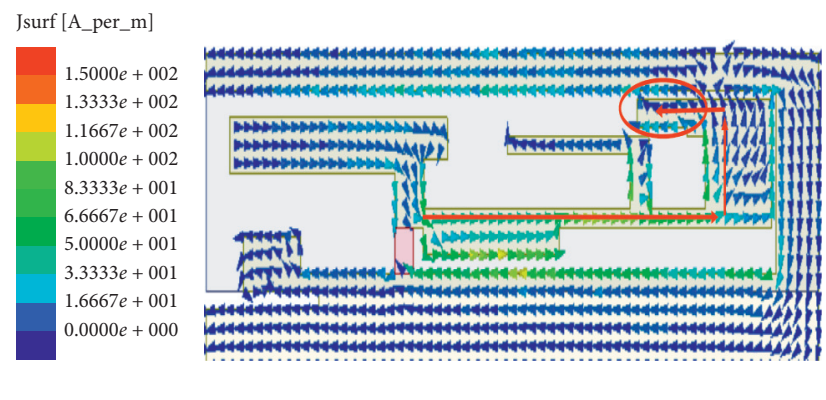

(b)
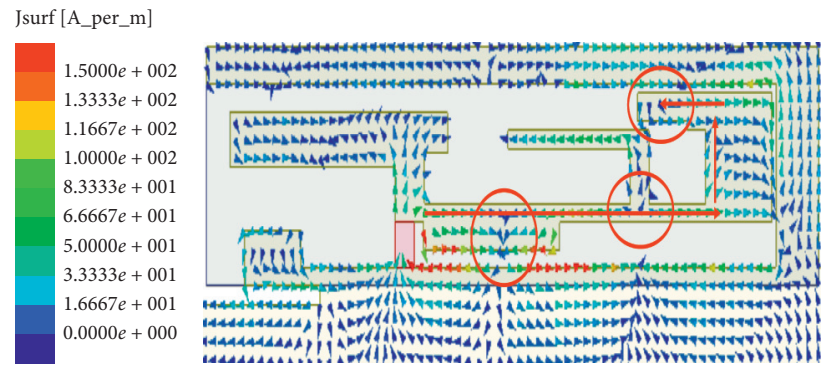

(d)

FIgURE 5: (a) $S_{11}$ values derived from the simulation considering different lengths of the right-side direct-fed arm of the developed antenna; current distribution of the direct-fed dipole at (b) 0.85 , (c) 2.69 , and (d) $4 \mathrm{GHz}$.

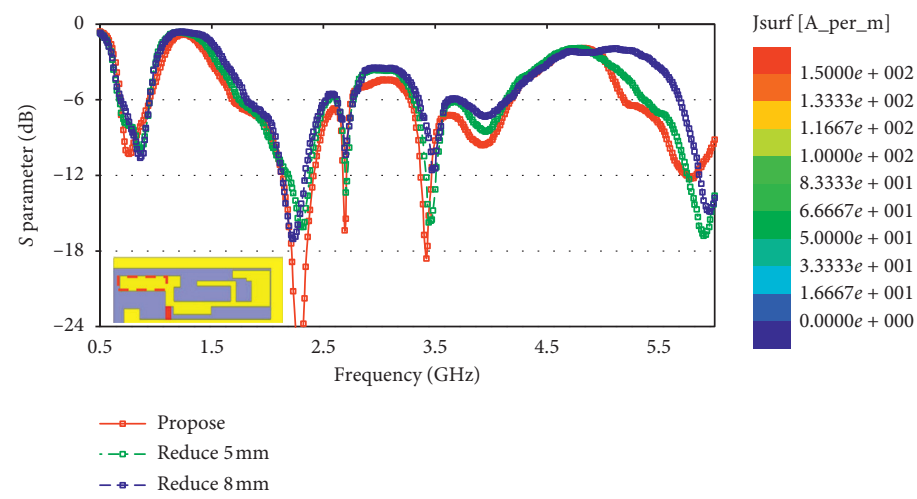

(a)

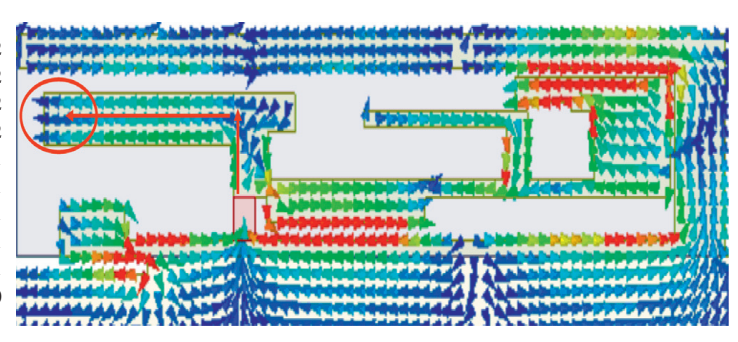

(b)

FIGURE 6: (a) $S_{11}$ values derived from simulation considering various lengths of the left-side direct-fed arm for the developed antenna; (b) left-side arm's current distribution at $5.5 \mathrm{GHz}$.

corresponding radiation efficiency exceeding 55\%. The gain was noted to be $0.83-5.67 \mathrm{dBi}$ in the middle band (at 1.71-2.69 GHz; Figure 10), with the corresponding efficiency being $55-83.6 \%$. The gain was determined to be above $3 \mathrm{dBi}$ and $0.9 \mathrm{dBi}$ at $3.2-4.2$ and $5.15-5.85 \mathrm{GHz}$, respectively, in Figure 11 with the corresponding efficiency ranging from $60 \%$ to $86.4 \%$. Measured resonant, gain, efficiency, and bandwidth are arranged in Table 2. The proposed antenna has suitable and stable radiation efficiency.
Performance was compared between present antennas with reference to some portable device antenna. Table 3 displays dimension, volume, bandwidth, $S_{11}$, and RLC element. In [1, 12, 14], LC element is used and bent-type structure greatly reduces dimension, while the volume is larger, and cover bandwidth is less than present antenna. In $[4,5,9,10]$, LC element is not used, and antenna occupies a smaller area, but volume and cover bandwidth are less than present antenna. Furthermore, present antenna can cover 


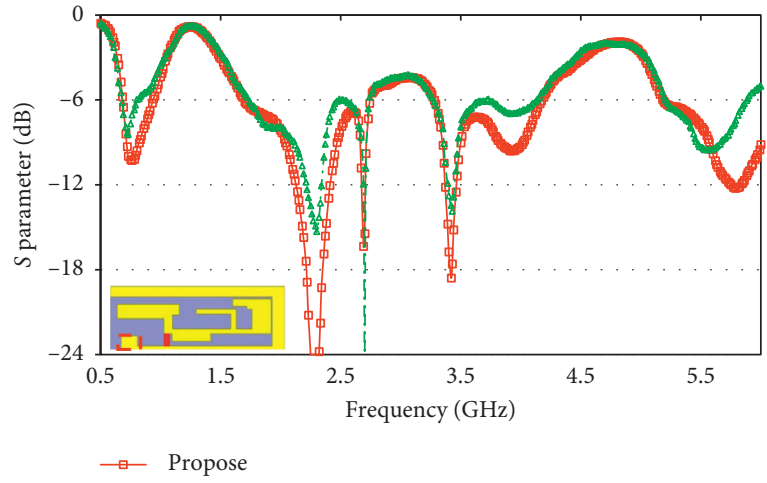

(a)

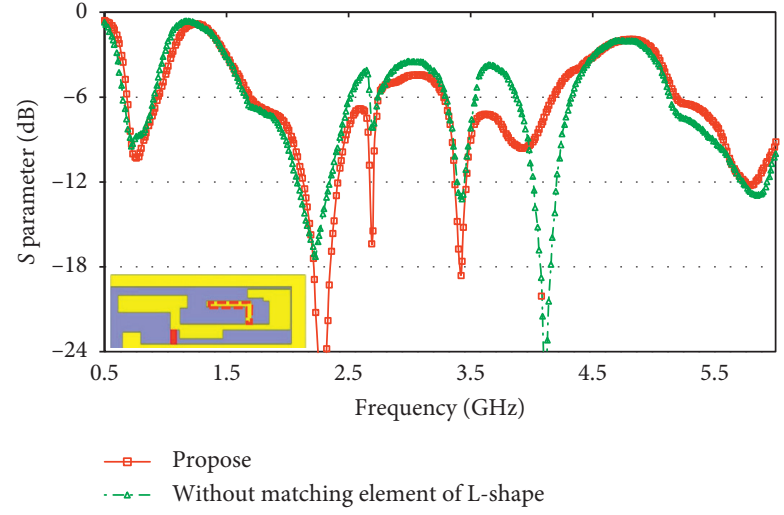

(b)

Figure 7: (a) $S_{11}$ values derived from simulation of developed antenna without and with a ground strip; (b) $S_{11}$ values derived from simulation of developed antenna without and with an inverted L-shaped matching element.
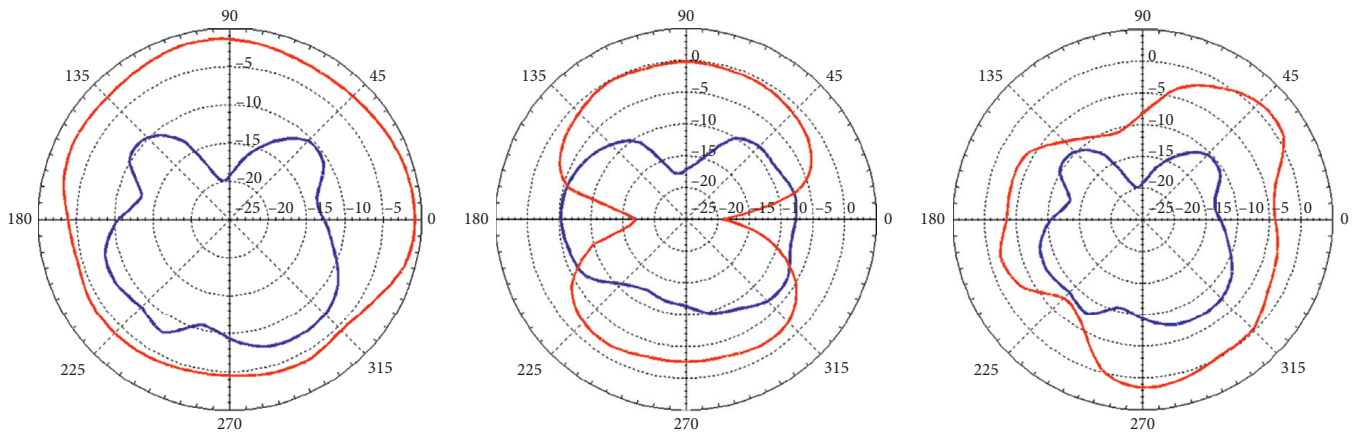

$\bar{E}_{\theta}^{E_{s}}$
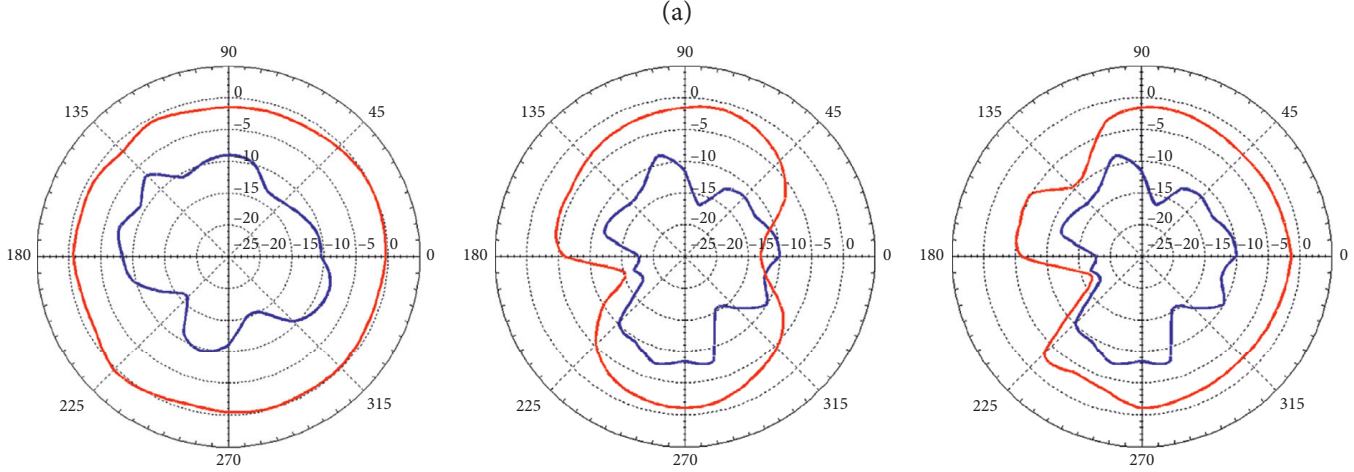

$E_{\theta}$
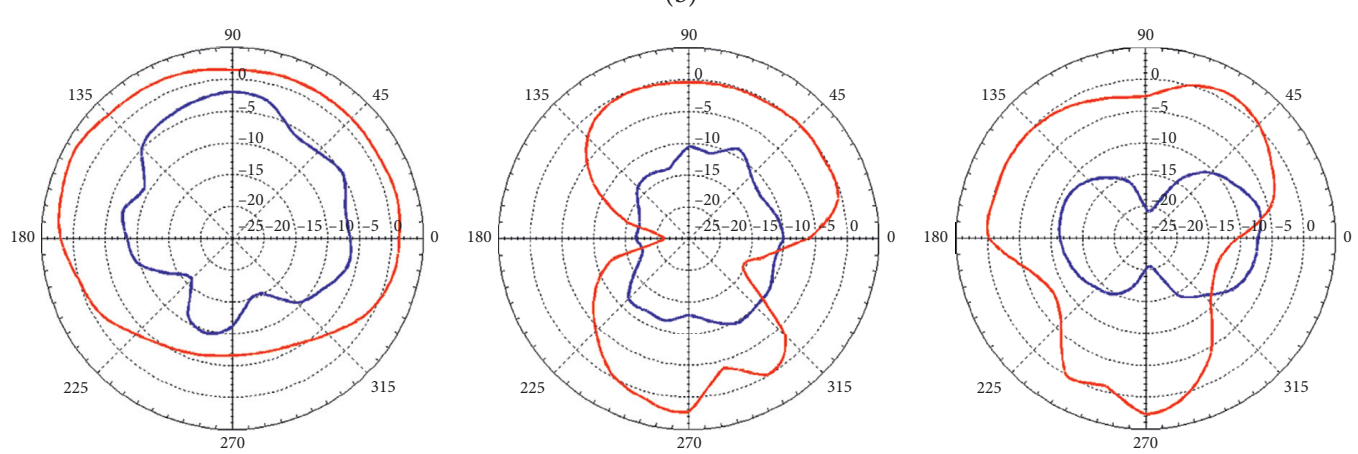

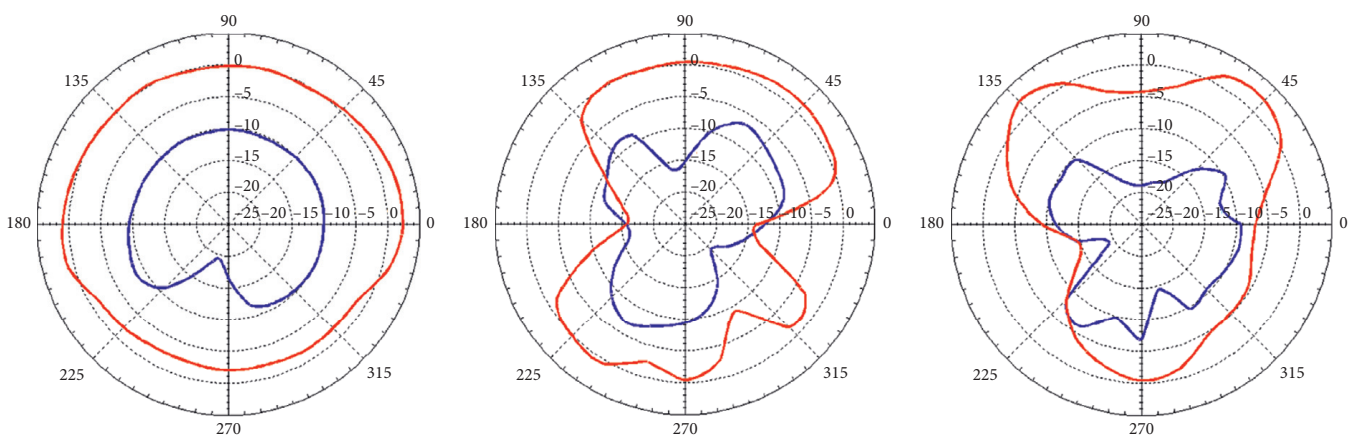

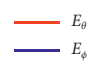
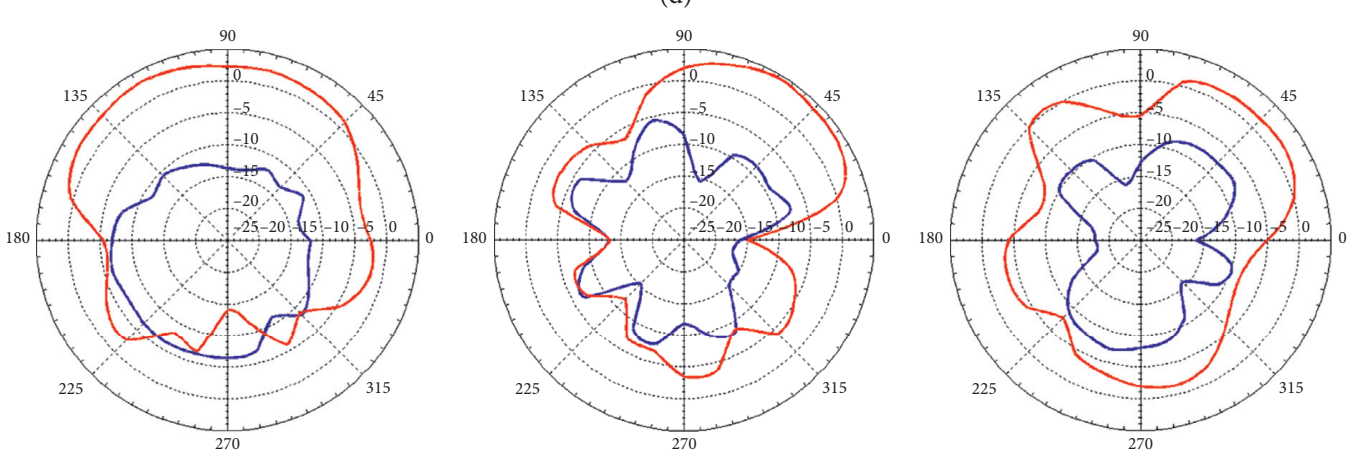

$\bar{E}_{E_{s}}$
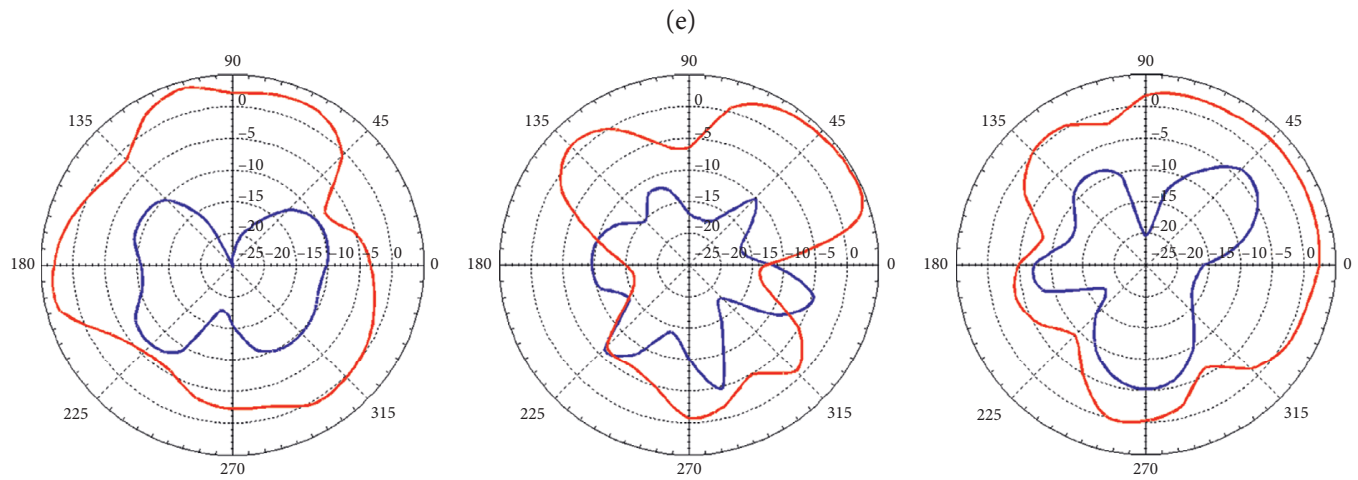

$-E_{o}$
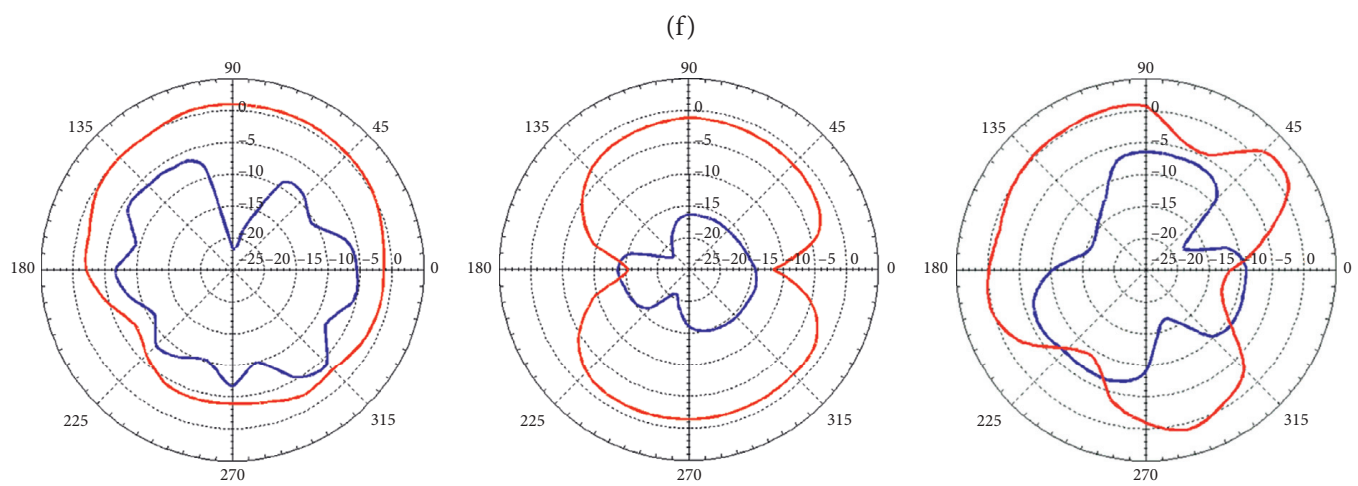

$\bar{E}_{E_{s}}$

(g)

Figure 8: Measured 2D antenna radiation patterns at $x-y, x-z$, and $y-z$ planes: (a) $760 \mathrm{MHz}$; (b) $850 \mathrm{MHz}$; (c) $2340 \mathrm{MHz}$; (d) $2690 \mathrm{MHz}$; (e) $3400 \mathrm{MHz}$; (f) $4000 \mathrm{MHz}$; (g) $5500 \mathrm{MHz}$. 


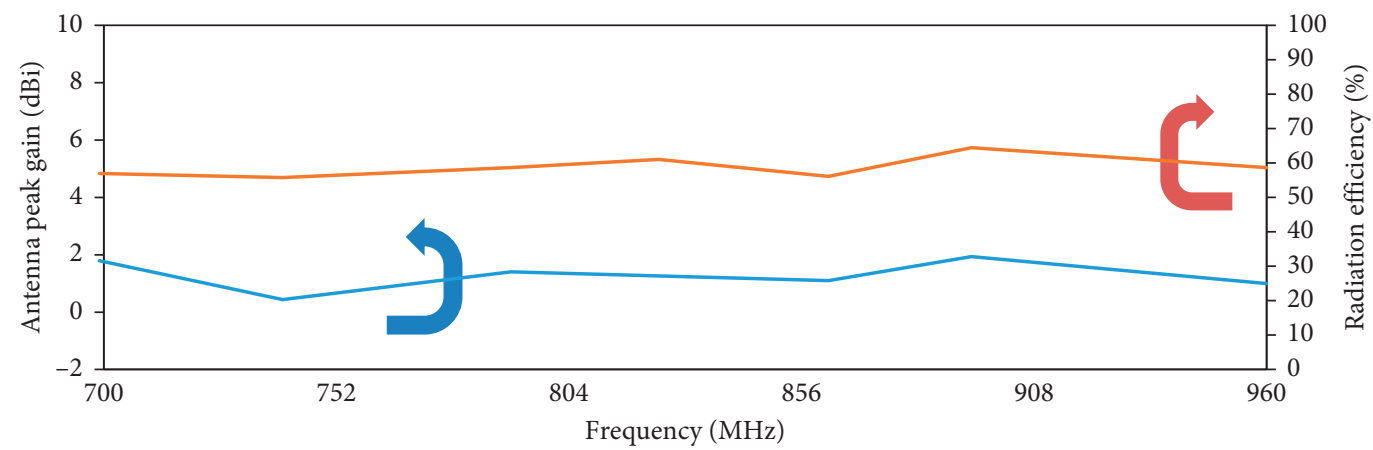

FIGURE 9: Gain and radiation efficiency measured for the developed antenna at $700-960 \mathrm{MHz}$.

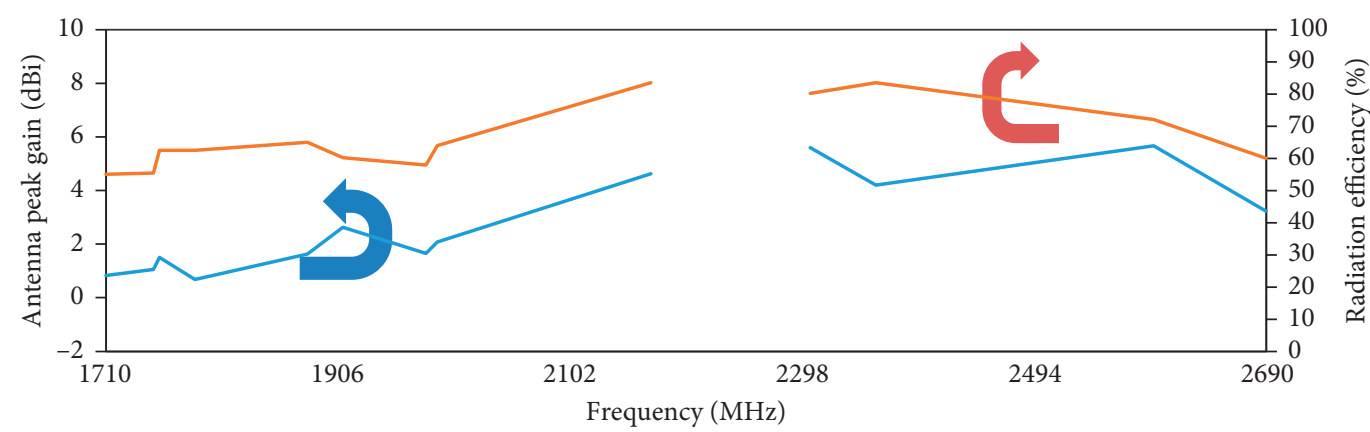

FIGURE 10: Gain and radiation efficiency measured for the developed antenna at $1710-2690 \mathrm{MHz}$.

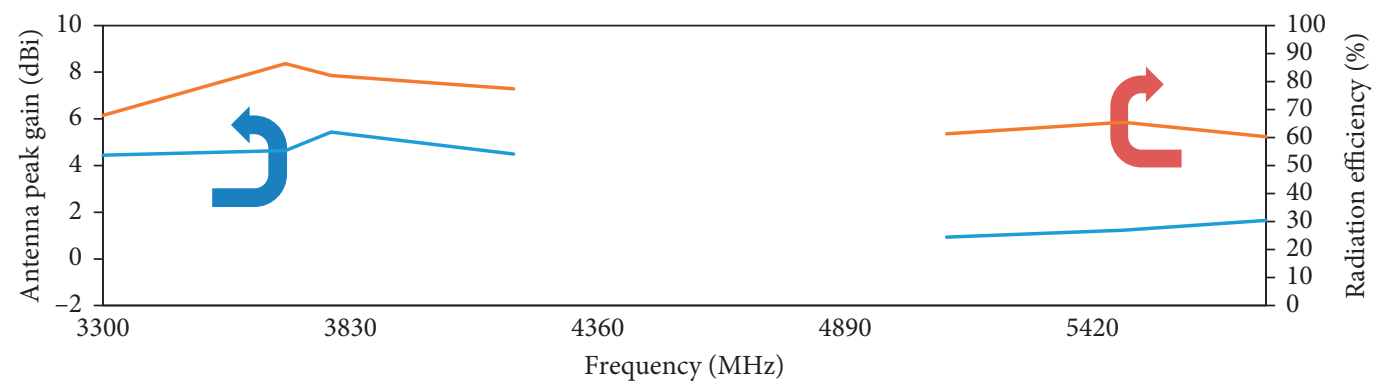

Figure 11: Gain and radiation efficiency measured for the developed antenna at 3300-5850 MHz.

Table 2: Arrangement of measured resonant, gain, efficiency, and bandwidth of proposed antenna.

\begin{tabular}{|c|c|c|c|c|c|}
\hline $\begin{array}{l}\text { Resonance frequency } \\
(\mathrm{GHz})\end{array}$ & Variation gain $(\mathrm{dBi})$ & $\begin{array}{c}\text { Variation efficiency } \\
(\%)\end{array}$ & Variation BW (GHz) & $\begin{array}{c}\text { Resonance } \\
\text { frequency } \\
(\mathrm{GHz})\end{array}$ & Variation gain $(\mathrm{dBi})$ \\
\hline 0.76 and 0.85 & $1.51(0.43-1.94)$ & $0.3(55.8-56.1)$ & $0.262(0.698-0.96)$ & 0.76 and 0.85 & $1.51(0.43-1.94)$ \\
\hline 2.34 and 2.69 & $4.84(0.83-5.67)$ & $28.6(55.0-83.6)$ & $0.98(1.71-2.69)$ & 2.34 and 2.69 & $4.84(0.83-5.67)$ \\
\hline 3.4 and 4.0 & $0.97(4.45-5.42)$ & $18.4(68.0-86.4)$ & $0.9(3.3-4.2)$ & 3.4 and 4.0 & $0.97(4.45-5.42)$ \\
\hline
\end{tabular}

TABle 3: Comparison between the present antenna and reference antennas.

\begin{tabular}{|c|c|c|c|c|c|}
\hline Reference & Area $(\mathrm{mm})$ & Volume $\left(\mathrm{mm}^{3}\right)$ & Bandwidth $(\mathrm{MHz})$ & $S_{11}(\mathrm{~dB})$ & LC element \\
\hline [1] & $15 \times 28 \times 4$ & 1680 & $804-967 / 1665-3280$ & -6 & Yes \\
\hline [2] & $60 \times 15 \times 2.8$ & 2520 & $698-1100 / 1640-2830$ & -6 & No \\
\hline [4] & $55 \times 12 \times 5$ & 3300 & $794-962 / 1710-2730$ & -6 & No \\
\hline [10] & $32 \times 18 \times 3$ & 1728 & $824-960 / 1710-2170 /$ & -6 & No \\
\hline [12] & $60 \times 8 \times 5$ & 2400 & $800-960 / 1710-2580$ & -6 & Yes \\
\hline [11] & $75 \times 12 \times 4$ & 3600 & $798-787 / 2305-2400 / 2500-2690 / 3400-3600$ & -6 & No \\
\hline [14] & $30 \times 10 \times 3$ & 900 & $698-960 / 1710-2170 / 3400 \sim 3800$ & -6 & Yes \\
\hline [5] & $28 \times 15 \times 4$ & 1500 & $824-960 / 1710-2170 / 2300-2690$ & -6 & No \\
\hline [9] & $60 \times 7 \times 3$ & 1260 & $698-960 / 1710-2170 / 2300-2690$ & -6 & No \\
\hline Presents antenna & $65 \times 13 \times 0.4$ & 845 & $698-960 / 1710-2170 / 2300-2690 / 3300-4200 / 5150-5850$ & -6 & No \\
\hline
\end{tabular}


bandwidth (698-960 MHz, 1710-2690 MHz, 3300-4200 MHz, and $5150-5850 \mathrm{MHz}$ ) as well as smaller size and planer structure than other reference antennas.

\section{Conclusions}

In this paper, a low profile, planar, and small-size antenna design is proposed for $5 \mathrm{G}$ portable communication equipment. The proposed antenna uses seven resonant modes to cover the frequency ranges of $0.69-0.96,1.71-2.69,3.2-4.3$, and $5.15-5.85 \mathrm{GHz}$. The operating range of the antenna covers the LTE 700/2500, GSM, UMTS, C band (n77 and $\mathrm{n} 78$ ), and license-assisted access (LAA). The proposed antenna has small dimensions, two wide bands of operation, omnidirectional radiation in low-frequency bands, and reasonable antenna radiation efficiency and gain. The measured results of the proposed antenna signify its suitability for portable devices.

\section{Data Availability}

The data used to support the findings of this study are available from the corresponding author on request.

\section{Conflicts of Interest}

The authors declare that they have no conflicts of interest.
National Radio Science Meeting, pp. 1142-1143, Vancouver, Canada, July 2015.

[9] C.-C. Yu1, C.-Y. Huang, J.-H. Yang, C.-H. Hsu, and J.-H. Chen, "A low-profile antenna design for LTE/WWAN smartphone application," in Proceedings of the 2018 Progress in Electromagnetics Research Symposium (PIERS-Toyama), pp. 454-457, Toyama, Japan, August 2018.

[10] Y. Xu and H.-M. Zhou, "Multiband printed loop mobile phone antenna for LTE/WWAN/GNSS application," International Journal of Antennas and Propagation, vol. 2016, Article ID 1671273, 7 pages, 2016.

[11] W.-S. Chen and M.-H. Liang, "LTE/5G C-band MIMO antennas for laptop computers," in Proceedings of the 2018 International Symposium on Antennas and Propagation (ISAP), Busan, Republic of Korea, October 2018.

[12] D. Wu, S. W. Cheung, and T. I. Yuk, "A compact and lowprofile loop antenna with multiband operation for ultra-thin smartphones," IEEE Transactions on Antennas and Propagation, vol. 63, no. 6, pp. 2745-2750, 2015.

[13] K.-L. Wong and W.-Y. Chen, "Small-size printed loop-type antenna integrated with two stacked coupled-fed shorted strip monopoles for eight-band LTE/GSM/UMTS operation in the mobile phone," Microwave and Optical Technology Letters, vol. 52, no. 7, pp. 1471-1476, 2010.

[14] C.-Y. Tsai and K.-L. Wong, "Combined-type dual-wideband and triple-wideband LTE antennas for the tablet device," in Proceedings of the 2015 Asia-Pacific Conference on Antennas and Propagation, pp. 411-412, Bali Island, Indonesia, June 2015.

\section{References}

[1] Y. W. Liang and H. M. Zhou, "Small-size seven-band WWAN/LTE antenna with distributed LC resonant circuit for smartphone application," International Journal of Antennas and Propagation, vol. 2015, Article ID 630674, 9 pages, 2015.

[2] W. H. Zong, X. M. Yang, X. Xiao et al., "A wideband antenna with circular and rectangular shaped slots for mobile phone applications," International Journal of Antennas and Propagation, vol. 2016, Article ID 2975425, 9 pages, 2016.

[3] W. S. Chen, C. M. Cheng, D. H. Lee, C. L. Ciou, W. S. Sin, and G. Y. Cai, "Small-size meandered loop antenna for WLAN dongle devices," International Journal of Antennas and Propagation, vol. 2014, Article ID 897654, 7 pages, 2014.

[4] Y. Hong, J. Tak, J. Baek, B. Myeong, and J. Choi, "Design of a multiband antenna for LTE/GSM/UMTS band operation," International Journal of Antennas and Propagation, vol. 2014, Article ID 548160, 9 pages, 2014.

[5] Y. Xu, Y.-W. Liang, and H.-M. Zhou, "Small-size reconfigurable antenna for WWAN/LTE/GNSS smartphone applications," IET Microwaves, Antennas \& Propagation, vol. 11, no. 6, 2017.

[6] J. Kulkarni, R. Seenivasan, V. Abhaikumar, and D. R. P. Subburaj, "Design of a novel triple band monopole antenna for WLAN/WiMAX MIMO applications in the laptop computer," International Journal of Antennas and Propagation, vol. 2019, Article ID 7508705, 11 pages, 2019.

[7] K.-L. Wong and Z.-G. Liao, "Small-size dual-wideband arm antenna with inductive and capacitive feeding branches for long term evolution tablet computer application," Microwave and Optical Technology Letters, vol. 57, no. 4, 2015.

[8] J.-H. Lu and Y.-M. Yan, "Planar LTE/WWAN arm antenna for 4G tablet computer," in Proceedings of the 2015 IEEE International Antennas and Propagation \& USNC/URSI 